\title{
An Investigation of Professional Problems of Physical Education and Sports Teachers and Effects of These Problems on their Performance and Motivation
}

\author{
Murat Kul ${ }^{1}$, Sevim Handan Yilmaz ${ }^{2}$ \& Fatih Yaşartürk ${ }^{3}$ \\ ${ }^{1}$ Department of physical education and sport teacher, Bartın University, Bartın, Turkey \\ ${ }^{2}$ Institute of Educational Sciences, Bartın University, Bartın, Turkey \\ ${ }^{3}$ Department of physical and sport teacher, Bartın University, Bartın, Turkey \\ Correspondence: Fatih Yaşartük. Department of physical and sport teacher, Bartın University, Bartın, Turkey. \\ Tel: 90-055-5499-5348. E-mail: fyasarturk@ bartin.edu.tr.
}

Received: July 28, 2018

Accepted: August 10, $2018 \quad$ Online Published: August 29, 2018

doi:10.5539/hes.v8n4p23

URL: https://doi.org/10.5539/hes.v8n4p23

\begin{abstract}
The purpose of this research is to analyze professional problems faced by the physical education and sports teachers and effects of these problems on their performance and motivation. 41 physical education and sports teachers working in the province of Bartın participated in the research. Interview method was used in this study which was designed with the "phenomenology" concept for exploration - benefited from the interview method. Descriptive analysis and content analysis methods were used during the analyze of the data obtained. the most important problems that physical education and sports teachers face may be listed as; school administration's underestimation of physical education course, lacking of the qualification needed to inspect this course, parents' focus on academic achievement and therefore their underestimation towards physical education course, parents' failure to motivate their children towards doing sports, non-availability of sport facilities and course tools and equipment, low weekly course hours, frequent change of curriculum, students' desire to do extracurricular activities during the course and inadequacy of in-service and seminar programs. It was determined that; due to the problems they face with school management $46 \%$ of the participants, due to the problems they face with the parents $76 \%$ of the participants, due to the problems they face with the students $49 \%$ of the participants, due to the problems they face with the curriculum $44 \%$ of the participants, due to the problems they face about the facility and course tools and equipment $68 \%$ of the participants, due to the problems they face about the inspection $22 \%$ of the participants, due to the problems they face with the provincial directorates of sports $56 \%$ of the participants, due to the problems they face about the in-service programs $27 \%$ of the participants were negatively affected in terms of performance and motivation.
\end{abstract}

Keywords: motivation, performance, physical education and sports

\section{Introduction}

The changes and developments that are taking place today are pushing the individual to keep up with the current conditions. Education is needed to adapt to these new situations and to prepare for life. Education is at the forefront of the principles that are indispensable in the path of modern societies. Since the investment made in human beings is a collective investment, every society has to best meet the education needs of its citizens in order to be able to continue its life. Education involves the individual to be raised in a way adapting into the society. Education is a process of acquisition which comprises the objectives such as to help people adapting to the society, to identify themselves in a psychological and cultural way, by learning their responsibilities to equip them with the behaviors necessary to make their lives happy (Keşke, 2007). For this reason, it is inevitable that economic productivity, high labor force and the number of qualified people and cultural richness are high in educated societies.

Raising qualified manpower is one of the most basic functions of education. Qualified manpower requires being physically, mentally and spiritually healthy. Considering this fact, physical education and sports are integrated and it is seen that they complement each other. The targets of both educations is parallel, to provide personality training through physical education and to benefit the society through leisure and play activities (Açak, 2005,As 
cited in: Karademir et al., 2010). Physical education is the education of the whole personality. Through physical education course, students are thought how to use their bodies in the most effective and efficient way, how to move properly, to be happy and ethical individuals and to exhibit positive mental and emotional development. For this reason, physical education and sports courses have an important place in the education system (Kaya et al., 2015). As a concept, physical education is expressed as a set of physical activities aiming to raise individuals as bodily, spiritually and physically developing individuals that enable them to develop in a balanced way without compromising the integrity of the organism (Açak, 2006).

The main target of physical education and sports is to ensure balanced physical, mental and social development of human which is the basic element of social and cultural development in contemporary education. For this reason, physical education and sports courses have an important place in the education system. Physical education and sports courses must be used efficiently in order to reach the goals of the curriculums. Accordingly; the most important element is the physical education and sports teachers in the educational institutions. Physical education and sports teachers are the individuals who are responsible for ensuring instructional cohesion, conducting sportive activities and minimizing the problems encountered in sports environment (Yüzüak, 2006).Physical education and sports teachers, who move in the framework of contemporary educational understanding, should have a number of qualifications instead of just acting as teachers carrying out the teaching activities. This is because the qualifications of the physical education and sports teachers - who have an active communication process with the students, enable the organizing of sports events and due to the nature of their job, should be in communication with the environment - will undoubtedly be of great importance (Ünlü, 2008). Today, a teacher-centered structure is also present in teaching-learning activities. In other words, the teacher is the director of learning. In order physical education and sports teachers to be able to create a good learning environment, it is expected that they will first identify the problems they encounter in the learning environment and generate solutions for these problems.

Along with the qualifications of a teacher for meeting the expectations in the leaning-teaching process; factors such as course environment, tools, materials used, curriculum and environment have a great importance in reaching the targets and increasing the efficiency as much as a teacher. It is known that physical education and sports teachers face with many problems and stress about their duties in their professional lives. Identification of problems faced by physical education and sports teachers will play an important role in solving problems related to physical education course. Because, in order to be able to create a good learning environment, it is necessary to establish a good learning environment first and in order to be able to create this environment, it is necessary to first identify the problems faced by the physical education teachers and to offer solutions. In this context; the purpose of the research, which is prepared by taking into consideration that taking the opinions of the teachers on the subject may be a guide for solving the problems; is to analyze the problems faced by physical education and sport teachers in their professional life and the effects of these problems on performance and motivation. It is thought that the results of this study will provide important contributions to the emergence of the problems faced by the physical education teachers and to the solution of these problems.

\section{Method}

\subsection{Pattern of Research}

Bartin province who work in physical education and sport that was made for teachers to send their views in this study used a qualitative research method. One of the qualitative research methods used in the research was case study design. It is a qualitative statement that we are aware of when we think of case studies but we want to investigate and explore the subjects for which we do not have detailed knowledge. A case-study is the answer to what are the experiences and conditions related to that subject, providing the outreach of the experiences that are experienced, and subjective experiences are important in the first place (Yıldırım \& Şimşek, 2013).

\subsection{Participants}

The working group constitutes a total of 41 physical education and sports teachers in the province of Bartın in 2017-2018 education and training period, 15 of them female and 26 of male who work in secondary schools of the Ministry of National Education.

\subsection{Data Collection}

One of the qualitative data collection tools is the "semi-structured interview form". During the preparation of the interview form, the related field was reviewed and the physical education and sports teachers were exchanged ideas. The final form of the 9 question form was prepared by 4 expert academicians in the field. Each question was asked whether the performance and motivations were affected. Sound recordings were taken from the 
negotiations. The interview questions were as follows: "Problems in practice with physical education and sport teachers such as school management, parents, students, curriculum, facilities, course tools, youth sports provincial directorate, national education law regulations and personal rights, in-service training and seminar programs performance and motivation.

\subsection{Analysis of Data}

Descriptive analysis and content analysis methods were used to analyze the sound recordings obtained within the scope of the research. Accordingly, the participants were coded as "K" in terms of representation and each participant was given a number "K1, K2, K3, K4, and K5" beside the code. For this, the table for the data coding obtained from the discussion forum was first created. Listening to the voice recordings in the direction of the questions, the most frequently used words and concepts were identified and a coding table was created for each question. The themes were determined by using these concepts and comments were made on these themes. Teachers' opinions on the subject is reflected in the article in accordance with the descriptive analysis method.

\section{Findings}

Table 1. Distribution of the Participants by Gender, Type of School and Educational Institution They Serve

\begin{tabular}{llll}
\hline GENDER & FEMALE & $\mathbf{N}$ & $\mathbf{\%}$ \\
& & $\mathbf{1 5}$ & $\mathbf{3 6}$ \\
\hline \multirow{3}{*}{ TYPE OF SCHOLL } & MALE & 26 & 64 \\
& PRIVATE & 5 & 12 \\
EDUCATIONAL INSTITUTION & STATE & 36 & 88 \\
& SECONDARY & 21 & 51 \\
& HIGH & 20 & 49 \\
\hline
\end{tabular}

When the distribution of participants according to their demographic characteristics is examined in Table 1, it can be seen that $64 \%$ were male and $36 \%$ were female participants. It is seen that $88 \%$ of the participants serve in state schools, $12 \%$ in private schools, $49 \%$ in high schools and $51 \%$ in secondary schools.

Table 2. Distribution of Participants by Age and Term of Office

\begin{tabular}{clll}
\hline AGE & & $\mathbf{N}$ & $\mathbf{\%}$ \\
& $20-25$ & 4 & 10 \\
\hline TERMS OF OFFICE & $26-30$ & 3 & 7 \\
& $31-35$ & 8 & 20 \\
& $36-40$ & 14 & 34 \\
& $41-45$ & 5 & 12 \\
& $46-50$ & 5 & 12 \\
& 50 and above & 2 & 5 \\
& $1-5$ years & 8 & 20 \\
6-10 years & 7 & 17 \\
& $11-15$ years & 8 & 20 \\
& $16-20$ years & 12 & 28 \\
& $21-25$ years & 2 & 5 \\
& 26-30 years & 2 & 5 \\
& 30 and above & 2 & 5 \\
\hline
\end{tabular}

When Table 2 is examined, it can be seen that age of $10 \%$ of the participants are between $20-25,7 \%$ are between 26-30, $20 \%$ are between $31-35,34 \%$ are between $36-40,12 \%$ are between $46-50$ and $5 \%$ are 50 years and above. $20 \%$ have been serving as a teacher for $1-5$ years, $17 \%$ have been serving as a teacher for 6-10 years, $20 \%$ have been serving as a teacher for 11-15 years, $28 \%$ have been serving as a teacher for $6-20$ years, $5 \%$ have been serving as a teacher for $21-25$ years, $5 \%$ have been serving as a teacher for $26-30$ years and $5 \%$ have been serving as a teacher for 30 years and above. 
School Administration's negative view against sports and deeming physical education and sports course as unneccessary course,

School management's focus on academic achievement and therefore, paying pay more attention to other subject courses

Not paying adequate attention to physical education and sports course,

Inadequate source allocated from the school budget for the purchase of teaching equipment and materials,

Deeming success of this course equivalent to the success of the school teams.

Figure 1. Participants' Problems with School Management and Whether Their Performance and Motivation are affected by These Problems

$46 \%$ of the participants are negatively affected by these problems, $54 \%$ of the participants are not afected by these problems

Figure 1. Participants state that; the school administration has a negative attitude towards sports and that they see physical education and sports course as an unnecessary lesson, since the school administration is more focused on academic achievement, they pay more attention to other subject courses and therefore do not pay adequate attention to physical education and sports course, the amount of source allocated from the school budget for the purchase of teaching equipment and materials is insufficient and success of this course is deemed equivalent to the success of the school teams. It has been identified that while performance and motivations of $46 \%$ of the participants were affected negatively by these problems, performance and motivations of $54 \%$ of the participants were not affected by these problems they faced.

Deeming physical education and sports courses as an unnecessary lesson and focusing to the academic achievement

Exhibiting a negative attitude towards their children's participation in sports activities, not supporting the activities,

Expecting high grades for this course all the times.

Worrying their children may get injured during the lesson and become sick due the unfavorable weather conditions,

Deeming sports activities as a waste of time and not willing to let their children participate to the sports activities conducted outside of the province,

Figure 2. Participants' Problems with Parents and Whether Their Performance and Motivation are affected by These Problems 
$76 \%$ of the participants are negatively affected by these problems, $24 \%$ of the participants are not affected by these problems,

Figure 2. Participants state that parents deem physical education and sports courses as an unnecessary course and for this reason, they do not support their children in doing sports, they have a negative attitude towards their children's participation in sports activities, they are more focused on academic achievement and therefore they deem physical education and sports lessons as a waste of time, especially they do not want to let their children to participate to the sports activities which are conducted outside of the province and therefore avoid providing necessary permissions, additionally, they worry their children getting injured during the course and become sick due the unfavorable weather conditions and they expect high grades for this course all the times. It has been identified that while performance and motivations of $76 \%$ of the participants were affected negatively by these problems, performance and motivations of $24 \%$ of the participants were not affected by these problems they faced.

The favorite course of the students is physical education and sports.

Students deeming this course as a free-time course and not willing to adhere to the curriculum,

Willing to pass this course with a high grade and never accepting low grades,

Not willing to adhere to the curriculum and willing to do the activities they like more,

Not wearing appropriate clothes and not attaching importance for clothing.

Figure 3. Participants' Problems with Students and Whether Their Performance and Motivation are affected by These Problems

$49 \%$ of the participants are negatively affected by these problems $51 \%$ of the participants are not affected by these problems

Figure 3. Participants stated that their problems about the curriculum are; low weekly course hours, long curriculum and therefore, unable to transfer content of the curriculum to the students within that period, continuous change of curriculum and teachers not to be informed about those changes and their hard adaptation to this situation, unable to implement curriculum in the schools where sports hall and course materials are not available. It has been identified that while performance and motivations of $54 \%$ of the participants were affected negatively by these problems, performance and motivations of $46 \%$ of the participants were not affected by these problems they faced. 
Low weekly course hours,

long curriculum and therefore, having difficulties in transfering content of the curriculum to the students within that period,

Difficult adaptation of the teachers to the frequently changing curriculum

Unable to implement curriculum in the schools where sports hall and course materials are not available.

Figure 4. Participants' Problems with Curriculum and Whether Their Performance and Motivation are affected by These Problems

$54 \%$ of the participants are negatively affected by these problems, $46 \%$ of the participants are not affected by these problems

Figure 4. Participants stated that their problems about the curriculum are; low weekly course hours, long curriculum and therefore, unable to transfer content of the curriculum to the students within that period, continuous change of curriculum and teachers not to be informed about those changes and their hard adaptation to this situation, unable to implement curriculum in the schools where sports hall and course materials are not available. It has been identified that while performance and motivations of $54 \%$ of the participants were affected negatively by these problems, performance and motivations of $46 \%$ of the participants were not affected by these problems they faced.

Non-availability of sports hall

Inadequate tools and equipment that may be used during the course

Unable to perform course during unfavorable weather conditions,

Unable to implement curriculum,

Figure 5. Participants' Problems with Facility, Tools and Equipment and Whether Their Performance and Motivation are affected by These Problems

$68 \%$ of the participants are negatively affected by these problems, $32 \%$ of the participants are not affected by these problems.

Figure 5. Participants stated that the biggest problem they faced in their professional life is related to the physical conditions of their schools. K5 emphasized this situation saying that "The biggest dream of a physical education teacher is a school with a sports hall". Participants stated that the problems they encounter are; non-availability of the sports hall in the schools they serve, inadequacy of materials which can be used during the class, inability to perform the course in unfavorable weather conditions and cannot follow the curriculum due to this reason. Participants stated that collection of sports fees from the students was a supporting factor for procurement of class materials and teachers are being affected negatively since such collection has been prohibited and additionally that specified that restoration of this practice will be beneficial for material procurement. It has been 
identified that while performance and motivations of $68 \%$ of the participants were affected negatively by these problems, performance and motivations of $32 \%$ of the participants were not affected by these problems they faced.

Inspectors do not have the physical education and sports background,

Out-of-field inspectors not having adequate knowledge and equipment on physical education and sports course

Inspection to be performed in a few classes during the year

Figure 6. Participants' Problems with Inspection and Whether Their Performance and Motivation are affected by These Problems

$22 \%$ of the participants are negatively affected by these problems, $78 \%$ of the participants are not affected by these problems

Figure 6. Participants stated that the biggest problem they face is that the inspectors do not have the physical education and sports background. Participants indicated that they are adversely affected by the fact that inspectors are out of their field and inspectors do not have adequate knowledge and equipment on physical education and sports course. Participants stated that inspection is performed in a few classes during the year and such inspection remains inadequate to understand and pass a judgment on the teacher and that the inspection has to be performed spreading into the course of time. It has been identified that while performance and motivations of $22 \%$ of the participants were affected negatively by these problems, performance and motivations of $78 \%$ of the participants were not affected by these problems they faced.

Directorates failing to fulfil schools' trainer demands,

Having difficulty in getting in contact with the Provincial Directorates of Sports

Not getting adequate responds for the requests with regards to using the sports halls of the Provincial Directorate of Sports

Allowances remaining much below the amount needed to meet their needs.

Figure 7. Participants' Problems with Provincial Directorate of Sports and Whether Their Performance and Motivation are affected by These Problems

$56 \%$ of the participants are negatively affected by these problems, $44 \%$ of the participants are not affected by these problems

Figure 7. Participants stated that provincial directorates of sports fails to fulfill the schools' trainer demand, they face difficulties in ensuring adequate communication with provincial directorates of sports and they consider directorates remain inadequate with regards to this subject, they are not able to receive an answer for their requests about using the sports halls of the provincial directorates of sports, correspondences and information about the school sports activities are made delayed. They stated that the most important factor with regards to the provincial directorates of sports and conducting the school sports activities is allowances which affects their performance and motivation significantly. Allowances remaining much below the amount needed to meet their 
needs constitutes a significant problem for physical education and sports teachers. It has been identified that while performance and motivations of $56 \%$ of the participants were affected negatively by these problems performance and motivations of $44 \%$ of the participants were not affected by these problems they faced.

Participants do not have adequate information about their personal rights .

They do not have problems with regards to their personal rights,

Although it is not a problem for them, participants demands with regards to improvement of their conditions.

Figure 8. Participants' Problems about Personal Rights and Whether Their Performance and Motivation are affected by These Problems

Figure 8. When the answers of the participants are analyzed, it can be seen that participants stated that they do not have adequate information about their personal rights and they do not have problems with regards to this subject. Although it is not a problem for them, participants demands with regards to improvement of their conditions.

In-service trainings to be performed in more central locations and more frequently.

Programs to remain insufficient for the teachers,

Participation difficulties since they are organized outside of the province,

Trainings conducted outside of the province being carried out in the mood of holiday,

Figure 9. Participants' Problems about In-Service Training and Whether Their Performance and Motivation are affected by These Problems

$27 \%$ of the participants are negatively affected by these problems, $73 \%$ of the participants are not affected by these problems

Figure 9. Participants stated that; delayed curriculum correspondences, these curriculums remain inadequate for the teachers, participation difficulties since these are organized outside of the province, the trainings provided outside of the province are carried out in the mood of holiday and the instructors remain inadequate about the field knowledge are the problems they encounter during in-service training and seminar programs. They stated that such programs have to be carried out in a more central location and more frequently and they desire everyone should have the opportunity to participate to the programs equally. It has been identified that while performance and motivations of $27 \%$ of the participants were affected negatively by these problems, performance and motivations of $73 \%$ of the participants were not affected by these problems they faced.

\section{Discussion}

In this part of the study, the previous researches in the literature have been examined. The same and different results are discussed. When the studies are examined, the results are mostly similar to the results of the study we have done. 
In the study conducted by Aydoğan (2006), it was aimed to investigate the problems related to vocational, school administration and structure of physical education and sport teachers and problems related to students. It has been observed that the problems faced by physical education and sports teachers are at the beginning of the problems originated from physical conditions. As it is understood from this, the course tools and sports facilities for physical education and sports teachers have an important place in the education phase and it has been found out that female teachers have more problems than male teachers in the research. Similarly, it has been observed that female physical education and sport teachers are experiencing more problems with male profile and sports teachers than with student profile. Another work by Yıldız (2012) supports Aydoğan and the work we have done. In the study, it was concluded that the lack of facilities, materials and lesson hours was the most important problem faced by the physical education and sports teachers in their teaching methods.

Çolakoğlu (2006) analyzed the problems that physical education and sports teachers encounter during their practices in their schools and it was been seen that $60.8 \%$ of the physical education and sports teachers "face monetary problems during sports activities in their schools" and $73.4 \%$ of the physical education and sports teachers stated that "they find class hours allocated to the physical education course inadequate". In the study carried out by Demirhan (2014) to identify the problems encountered by the physical education and sports teachers in practice and their solution suggestions for these problems; it was determined that; school management underestimating the physical education and sports course, inspectors not having adequate qualification to evaluate the course, parents remaining uninterested against the course, teachers not having knowledge about their personal rights, students not bringing appropriate clothes to the course, female students remaining uninterested to the course, facility, material and equipment inadequacy, short class hours, inability to carry out class planning-execution-evaluation processes due to the excessive number of students, non-functionality of the group studies and inability to carry out extracurricular studies as a result of students' participation to the private teaching institutions are the most significant problems that physical education and sports teachers encounter in practice. In the study carried out by Hakyemez (2010) aiming to identify the problems that physical education and sports teachers encounter during their professional lives, it was determined that monetary gain, class hours and class materials and equipment are inadequate.

In the study carried out by Yaşar (2008), it was aimed to identify the problems that physical education and sports teachers encounter during their professional lives. The teachers participated to the study stated that inadequacy of sites and class hours are the principal problem that they encounter in their professional life. The research conducted by Atasoy (2008) aimed to identify the problems faced by the physical education and sports teachers working in Kurşehir provincial center with their occupational life and physical education course applications. In the survey, the most common problems faced by teachers are the lack of incentives to participate in sports activities of children, such as inadequate field and facility deficiencies, as well as other work and work that we have done. Problems faced by physical education and sports teachers in Sakarya province have been investigated by Kul (2008). Problems that they see as problems are similar to the results of previous studies and there are problems such as facility insufficiency, inadequate weekly course hours, equipment inadequacy, parents' participation in this course is unnecessary. The results are similar to the results of the work we do.

In the study conducted by Erhan (2009), findings were found to be in parallel with those of the others. Similar to the study we conducted in Eastern Anatolia, which is different from the one we did in our studies, we aimed to examine the problems faced by the physical education and sports teachers working in the Eastern Anatolia region. room insufficiencies, the fact that the physical conditions of the schools are inadequate constitute an important problem in the region. The results are similar to other investigations as a result of being unrelated to the lesson. Kaya (2015) As a result of the work carried out by the teachers of physical education and sports for the determination of some professional problems, there are some professional problems of the physical education and sports teachers in terms of the problems related to the facilities and lesson resources, the curriculum, . It has been determined that physical education teachers are the most important problems of the physical education teachers because of the inadequate and incomplete facilities, tools and equipment, importance of school administrators and parents to physical education lessons, lack of communication between teachers and parents and insufficient teaching hours, with the results of the work we do.

In the study conducted by Çelik (2008), when the problems faced by physical education and sportsmen in professional life were examined, the following results were obtained; we can see that the problems faced by physical education and sports teachers are the same in the study of the biggest problems faced by school administrators and parents with regards to attitudes and behaviors to the classroom due to inadequate physical conditions of the school, lack of sports facilities, lack of teaching materials and materials. Ugur (2007) Analyzed the problems faced by the physical education and sport teachers with regard to classroom management, 
differently from the results of the research, we found that the physical education and sport teachers used the reactive models as the result of examining the teaching models they used and the problems they encountered were the class processing lack of support from the facilities, equipment, physical space, administration and other branch teachers, families 'lack of interest, students' problems with clothes and the failure to implement physical education curriculum programs fully.

In the research done by Son (2010), it was determined that the physical education and sports teachers in Balikesir were confronted with the problems in the profession and they were ordered to take care of the physical education and sports lesson because of the exams, the parents do not have the necessary knowledge and equipment related to this course, the lack of classroom equipment and materials and the problems of school management are the main topics of the school administrators' class, and these problems are the same with the results of our work.In the research conducted by Çınar (2011), the occupational problems faced by the physical education teachers working in the primary schools in the province of Sivas were determined and almost the same results were obtained with other studies. Problems such as lack of balance, lack of physical education and sports lessons and lack of lecture hours The results are in line with the work we do. Taymaz (2011) observed that physical education and sports teachers had the notion that physical education and sports teachers would negatively affect their participation in physical education and sporting activities, as opposed to the one we studied in the examination of the problems they faced in the profession. .

Ulucan et al. (2012) In Kırşehir province, it is aimed to investigate the problems that have been done to determine the problems of physical education and sports teachers. At the end of the research, it was determined that physical education and sports teachers had a medium level problem about school physical conditions, students, students and parents. Demirhan et al. (2014), it is concluded that the inspectors who have obtained the results which are parallel with the study and the supervisors that the physical education and the sports lesson are unnecessary and the same approach in the same way in their parents are insufficient for the field.

\section{Conclusions}

In this study, the problems that Physical Education and Sports Teachers encounter in their Professional Life and their opinions about how these problems affect their performance and motivation are tried to be identified and the problems they encounter during this process are analyzed. The main finding obtained in this study is that the physical education and sports teachers have a point of view with regards to the problems they face during their professional lives. The problems they encounter are; school administrations and parents give a particular importance to the academic achievement and therefore they see physical education and sports courses unnecessary compared to the other courses, therefore they do not support to the activities which are going to be performed, parents are not willing to let their children participate to the matches which are carried out outside of the province, they worry their children getting injured during the physical education and sports class and may fall behind the other courses, parents expect that their children to get high grades from this course, students do not want at adhere to the curriculum since they feel themselves free in this course, students do not wear appropriate clothes during the course. On the other hand, the problems they encounter about the curriculum are; class hours remain inadequate and therefore they face difficulties in completing the curriculum, frequent changes are made in the curriculum and they have difficulties in adapting such changes, non-availability of sports halls and materials that are needed for class and this situation poses a significant obstacle against implementation of the curriculum. Inspectors being out of the physical education and sports field and failing to have sufficient field knowledge, the amount of travel allowance provided for sports competitions remaining inadequate to meet the needs, in-service training and seminar programs to be conducted out of the province and therefore they have difficulties in participating to these programs pose problems for the participants and their performance and motivation are adversely affected by these problems.

\section{Recommendations}

In the light of abovementioned data; the following suggestions have been developed in order to minimize the problems faced by physical education and sports teachers and to increase their performance and motivation.

School administration and parents should be made aware of the necessity of physical education and sports course, In this context; education programs with regards to the benefits of sports, its contributions and job opportunities in the field of sports may be organized, Activity programs aiming to raise and disseminate sports awareness in the community can be organized, For the resolution and efficiency of inspection related issues; inspections may be performed regularly by experts in the field of physical education and sports, Through generating sports awareness in the society, the importance placed to the sports and source allocated to the sports may be increased and this is possible with the enhancement of sports activity. 
Problems encountered may be struggled and course material and equipment deficiencies may be minimized through course purpose oriented material designs, In order to minimize the effects of lacking of a sports hall, students may be directed to the fields which can be performed outdoor and federations and student societies may be contacted in order to receive support about this issue.

\section{References}

Aydoğan, H. (2006). Physical Education Teachers' Problems Relating to Their Jobs (Application of Trabzon province). Materialized Master Thesis. Gazi University Educational Sciences Institute.

Açak, M. (2006). Handbook of Physical Education Teacher. Istanbul: Morpa Culture Publications.

Atasoy, M. (2008). Investigation of professional problems of physical education teachers and solution proposal (Kırşehir province example). Unpublished post graduate thesis. Gazi University Health Sciences Institute, Ankara.

Aydoğan, H. (2006). The Problems Faced by the Teachers of the Mathematics Education (Application of Trabzon). The Graduate Thesis.Gazi University Educational Sciences Institute, Ankara.

Çolakoğlu, T., \& Karaküçük, S. (2006). A Research on the Problems of Physical Education Teachers Relating to Practice in School. Gazi Physical Education and Sports Journal, 3, 35-48

Çelik, A. (2008). Examination of problems faced by physical education teachers in school and non-school activities (Trabzon province example). Unpublished post graduate thesis. Gazi University Educational Sciences Institute, Ankara.

Demirhan, G., \& Saçl1, Y. (2014). The Problems faced by Physics Teachers in Practice Problems and Suggested Solutions. Hacettepe University Journal of Faculty of Education, 29, 57-58

Erhan, S. E. (2009). The machinability of the physical education course in the provincial centers of Eastern Anatolia, the problems of the physical education teachers and their effect on student attitudes. Unpublished doctoral thesis. Gazi University Educational Sciences Institute. Ankara.

Hakyemez, Ö. (2010). Bedeneğiti and Sports Teacher of Professional Experiences Problems Encountered In (Kayserl example) were followed. Yayıml Degree tezi.gaz üniversitesi.eğit Sciences Institute, Ankara.

Kul, M. (2008). The Effects of Physical Education Teachers on Problems and Their Performance (Sakarya province example). Unpublished Master Thesis. Sakarya University Institute of Social Sciences, Sakarya.

Kaya, M., Bozdemir, R., Türkçapar, U., \& Demir, O. (2015). Examination of Some Professional Problems of Physical Education Teachers (Tokat Province). Journal of International Educational Science, 356-375. https://doi.org/10.16991/INESJOURNAL.172

Karademir, T., Coban, B., \& Kafkas, E. (2010). Investigation of the Relationship between Preservice Physical Education Teachers' Sense of Self-Efficacy and Professional Concerns, Inonu University. Journal of the Faculty of Education, 11(2), 93-111

Keşke, G. (2007). Instructional Methods and Relations of Teachers of Physical Education Teachers in Primary Schools (Gaziantep Case). Çukurova University, Institute of Health Sciences, Adana.

Ulucan, H., Türkçapar, Ü., \& Cihan, B. (2012). Examination of the Problems of the Teachers of the Physical Education in the Occupation (Kırşehir Illi Uygulaması). Dumlupınar University Social Sciences Institute, Kütahya.

Ünlü, H., \& Aydos, L. (2008). Classroom Management in Physical Education Class. International Human Sciences Magazine, 5, 10303-1305

Son, M. (2010). Physical Education Teachers' Professional Problems (Balikesir province example). Unpublished Master's Thesis. Gazi University Health Sciences Institute, Ankara.

Taymaz, H. (2011). Investigation of occupational problems of physical education and sports teachers working in state and private primary schools (Antalya province example). Unpublished post graduate thesis. Mehmet Akif Ersoy University Institute of Health Sciences. Burdur, 13(2), 265-277.

Yasar, G. (2008). Physical education teachers are asking about the school and stressing that their styles are in terms of some variables. The dissertation is incomplete master's thesis. Cukurova University Health Sciences Institute. Adana.

Yildiz, S. (2012). Examination of Self-Improvement Levels of Physical Education and Sport Teachers in Profession. Medicine Graduate Thesis.Mersin University, Institute of Health Sciences, Mersin. 
Yıldırım, A., \& ve Şimşek, H. (2013). Qualitative research methods in social science, Ankara.

\section{Copyrights}

Copyright for this article is retained by the author(s), with first publication rights granted to the journal.

This is an open-access article distributed under the terms and conditions of the Creative Commons Attribution license (http://creativecommons.org/licenses/by/4.0/). 